\title{
An Empirical Study on the Application of Lead-Acid Batteries to ESSs and Performance Improvement Methods
}

\author{
Hyun-Chul Jung ${ }^{* * * *}$ and Hoon Heo ${ }^{\dagger}$ \\ ${ }^{*}$ Smart Energy Team, Enterprise IT Performing Department, Korea Telecom, Seoul, Korea \\ ${ }^{* *, \dagger}$ Department of Control and Instrumentation Engineering, Korea University, Seoul, Korea
}

\begin{abstract}
In this paper, an approach to extend the life of lead-acid batteries through the elimination of sulfation with "rest time" using the pulse current of a conventional DPV (Differential Pulse Voltammetry) method is discussed. A new rest time without " 0 " current in "saw-tooth" pattern pulses is proposed to overcome the "0" current (blackout period), which is a shortcoming of DPV. This will enable the proposed method to be used in the loaded state. In the proposed approach, ESSs (Energy Storage Systems) were discharged for $5 \mathrm{~h}$ twice per day for 6 months on weekdays. To observe the changes in the lifespan of the systems, for the same period, the changes in the impedances of lead-acid batteries which were being charged e without charging and discharging were measure and compared. This study is focused on determining the effectiveness of lead-acid batteries as ESSs.
\end{abstract}

Key words: Energy storage systems, Sulfation, Smart grid, Pulse differential voltammetry, Rest time

\section{INTRODUCTION}

In recent years, there have been many blackouts during summer periods due to lower power reserve margins. These blackouts have the potential to be a major socio-economic issue. Various solutions have been implemented to prevent these blackouts. These range from improving the power-generation infrastructure on the supply side to reducing the power consumption during peak hours on the consumer side.

According to Korean energy-consumption patterns, the average diurnal rate of change in power consumption has reached approximately $57 \%$. To compensate for this gap in peak demand, the country relies on power generation using imported raw materials (LPG and oil), which are expensive. In other words, to satisfy the corresponding load fluctuation of $57 \%$, excluding the nuclear base load, costly raw materials

Manuscript received Jul. 29, 2014; accepted Feb. 26, 2015

Recommended for publication by Associate Editor Yujin Song.

${ }^{\dagger}$ Corresponding Author: heo257@korea.ac.kr

Tel: +82-2-3290-3974, Fax: +82-2-9297808, Korea University

*Smart Energy Team, Enterprise IT Performing Department, Korea Telecom, Korea

${ }^{* *}$ Dept. of Control and Instrumentation Eng., Korea University, Korea are required in order to meet the power generation capacity [1]. In many countries, this fluctuation often leads to the introduction of tariffs that are based on the time of use.

The solid red line in Fig. 1 illustrates the national power usage at different times of the day. The dotted red line shows the maximum capacity with a power generation of $87 \mathrm{GW}$. The grid is observed to be vulnerable to blackouts if a marginal reserve rate of less than $5 \%$ is maintained during the summer season. The use of ESSs (Energy Storage Systems) to store energy in batteries during the daytime, after which it is discharged during peak hours, would guarantee a sufficient energy reserve rate, leading to economic sustainability, as shown by the blue dotted line.

Recently, the IT infrastructure in various industries such as telecommunications companies, banks, IDCs (Internet Data Centers), industrial complexes, and even government offices have installed large numbers of lead-acid batteries for use as emergency backup batteries to ensure system reliability. When compared to lithium batteries, lead-acid batteries are more economical in terms of their durability and safety.

When these pre-installed batteries are applied as ESSs, a significant advantage is expected without the need for any additional investment. However, when lead-acid batteries are 


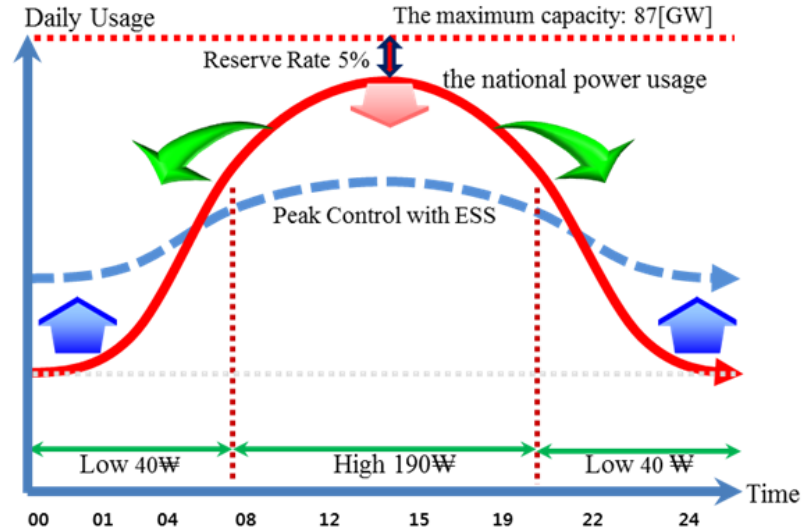

Fig. 1. Maximum domestic power supply and reserve rate with ESS effect.

used as ESSs, the frequent charge and discharge cycles will result in a significant decline in the lifespan of the batteries [2], [3]. In this paper, an enhanced method to improve the performance of lead-acid batteries is proposed and its practical implementation is discussed.

\section{INHERITED PROBLEMS AFFECTING LEAD-ACID BATTERY USED AS ESSS}

For lead-acid batteries to be used as ESSs, the following problems need to be resolved.

First, according to Peukert's law, the maximum dischargeable capacity of a lead-acid battery is proportional to the discharged current and the duration of the discharge. The maximum current that can be discharged per hour can be represented by Equation (1) [4].

$$
C_{p}=I^{k} \mathrm{t}
$$

where:

$C_{p}$ is the capacity at a one-ampere discharge rate, which is expressed in ampere-hours.

$I$ is the actual discharge current (i.e., the current drawn from the load) in amperes.

$k$ is Peukert's constant (dimensionless).

$t$ is the actual time required to discharge the battery, which is expressed in hours.

Based on Peukert's law, Table I shows the relationship between the total dischargeable current and the discharge current proportional to the discharge duration of a VGS-3000, which is a lead-acid battery. When the VGS-3000 AH is discharged under $0.1 \mathrm{CA}, 306 \mathrm{~A}$, a total of $3060 \mathrm{~A}$ can be discharged for $600 \mathrm{~min}$. However, when it is discharged under $1 \mathrm{CA}, 1204 \mathrm{~A}$, it takes only $60 \mathrm{~min}$ to reach the terminal voltage of $1.80 \mathrm{~V}$ (discharge termination voltage). Therefore, there is a difference of 2.5 times that of the dischargeable current [5]. In other words, the maximum dischargeable capacity of a lead-acid battery is based on the hourly discharge current.
TABLE I

Total Dischargeable Constant CuRrent over Discharge TIME [5]

\begin{tabular}{l|c|c|c|c|c|c|c|c|c}
\hline & $15 \min$ & $30 \min$ & 1h. & 2h. & 3 h. & 4h. & 5 h. & 8 h. & 10h. \\
\hline VGS 1000 & 702 & 587 & 453 & 320 & 250 & 212 & 176 & 122 & 102 \\
\hline VGS 1400 & 797 & 687 & 561 & 418 & 326 & 288 & 242 & 166 & 140 \\
\hline VGS 1600 & 881 & 786 & 652 & 477 & 379 & 329 & 281 & 189 & 160 \\
\hline VGS 2000 & 1085 & 983 & 803 & 597 & 479 & 413 & 346 & 240 & 204 \\
\hline VGS 2400 & 1301 & 1180 & 962 & 717 & 559 & 494 & 415 & 286 & 240 \\
\hline VGS 2600 & 1411 & 1279 & 1043 & 776 & 606 & 535 & 450 & 309 & 260 \\
\hline VGS 2800 & 1519 & 1375 & 1123 & 835 & 653 & 577 & 484 & 333 & 280 \\
\hline VGS 3000 & 1628 & 1474 & $\mathbf{1 2 0 4}$ & 895 & 718 & 619 & 519 & 360 & $\mathbf{3 0 6}$ \\
\hline
\end{tabular}

* Amperes to F.V $1.80 \mathrm{~V}$ per cell

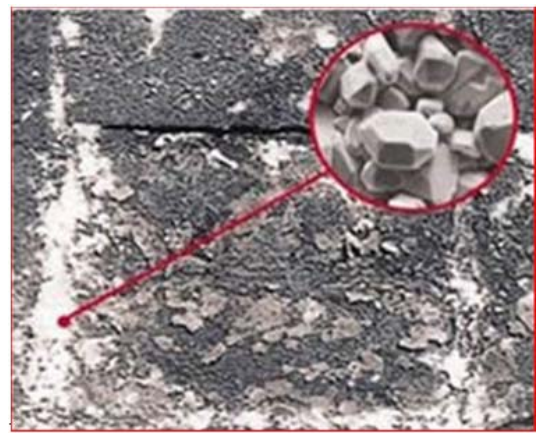

Fig. 2. Sulfation $\left(\mathrm{M}_{2}^{\mathrm{I}} \mathrm{SO}_{4}\right)$ coated on the surface of lead sulphate $\left(\mathrm{PbSO}_{4}\right)$.

Therefore, there is a need to adjust the hourly discharge rate.

Second, if the battery undergoes repeated discharging and recharging, white sulfate $\left(\mathrm{M}_{2}^{\mathrm{I}} \mathrm{SO}_{4}\right)$ is coated on the surface of the lead sulphate $\left(\mathrm{PbSO}_{4}\right)$, as shown in Fig. 2 [6]-[12].

Sulfation, which appears spongy in the initial stages, becomes crystallized in the barrier sulfation state and acts as an adhesive in the crystallized sulfation state as time passes. That is, unless the efficiency problems in the first stage and the sulfation problem in the second stage are resolved, lead-acid batteries cannot be used as ESSs.

\section{STUDY ON LEAD-ACID DISCHARGE EFFICIENCY AND LIFE-SPAN ENHANCEMENT}

\section{A. Study on Discharge Efficiency Using HESS}

Recently, to solve the problem of the shorter life cycles of the lead-acid batteries for EVs (electric vehicles), which is caused by continuous charging and discharging, several studies have been performed using discharge control circuits to improve their efficiency and longevity [13]-[23]. Fig. 3 shows an HESS (Hybrid ESS) circuit that was designed to carry out a performance test for batteries when the number of rapid charge and discharge cycles is reduced using the ultra-capacitors in existing hybrid EVs [20].

The charging and discharging of lead-acid batteries is done through a switch connected in series to a $36 \mathrm{~V}$ battery that 


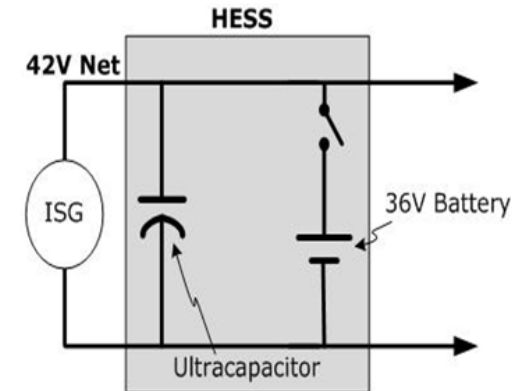

Fig. 3. Composite hybrid energy storage battery with parallel structure [20].

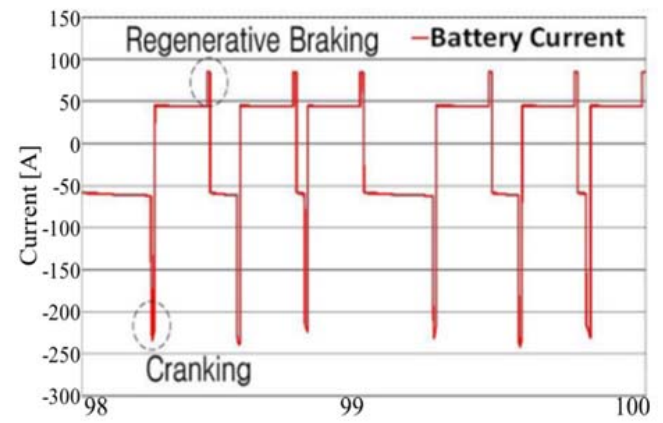

Fig. 4. Current flowing through the lead-acid battery alone [20].

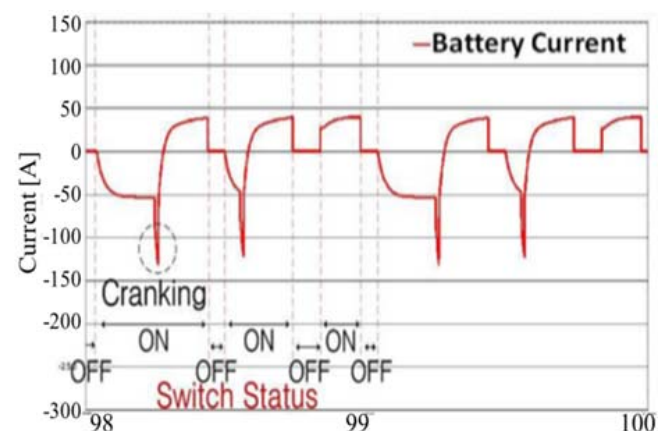

Fig. 5. Current flowing through the battery in the proposed HESS [20].

works only under the rated capacity of the charging/discharging current. Moreover, an "ultra-capacitor" traces the current above the rated current that is caused by load fluctuations. The EV used in the experiment is a mild hybrid EV that adopted a $3.5 \mathrm{~kW}$ rated ISG (Idle Stop and Go) considering the charging situation through the ESS [20].

Fig. 4 shows the charge/discharge wave patterns of the current in the case where only a VGS battery is connected.

Fig. 5 shows the charge/discharge wave patterns of the current in the case where a VGS battery and an ultra-capacitor are connected in parallel.

In Fig. 4, the battery needs to supply a large discharge current of approximately 239 A in order to crank the EV. However, in Fig. 5, the battery alone supplies current that is less than $150 \mathrm{~A}$. The remaining current of $89 \mathrm{~A}$ and the 3rd cranking current are all supplied by the ultra-capacitor.

Moreover, in Fig. 4, in the case of regenerative braking, several cases involve overcharging of the batteries by more

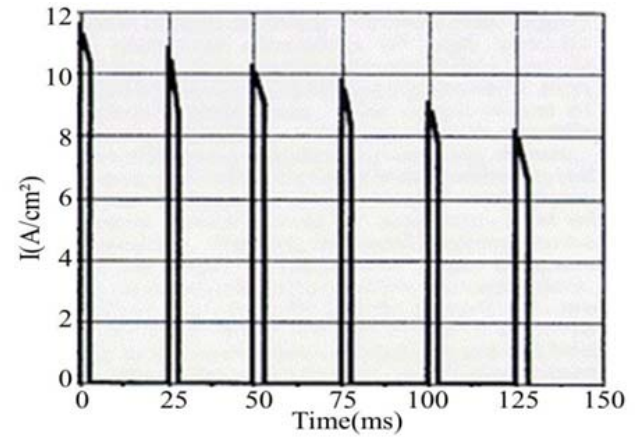

Fig. 6. Current impulse of a bipolar lead-acid battery subjected to voltage impulses. Pulse length $=3 \mathrm{~ms}$, rest time period $=22 \mathrm{~ms}$ [28].

than +50 A. However, while there were no such overcharging cases in Fig. 5, they were only charged to less than +50 A. Thus, tests were performed to extend the life spans of lead-acid batteries by preventing rapid discharges during cranking and rapid charges during regenerative braking. This was done by applying ultra-capacitors [20]-[22].

After experiments for cyclic discharges were performed, it was shown that the lead-acid batteries retained less than $80 \%$ of their initial capacity with only 7,104 discharge cycles. However, with the HESSs, the batteries retained $93 \%$ of their initial capacity even after 19,694 discharge cycles [20]. This study shows that the required number of discharge cycles increased when the rapid charge/discharge cycle of lead-acid batteries was suppressed. In Section 4, a method that has the same effect in power supply systems without the need for an ultra-capacitor is proposed.

\section{B. Study on the Suppression of Sulfation Using DPV}

Lead-acid batteries realize the effect of recycling by discharging impulse-type currents. This method is called DPV (Differential Pulse Voltammetry), and various studies on this method are being carried out. DPV is based on the principle that a battery is recovered by performing a pausing action called "rest time" [23]-[27]. Fig. 6 shows the wave pattern of a current being discharged by discharging an impulse-type voltage using the DPV method [28].

Another experiment performed using this DPV recycling method shows that the change of sulfation can be verified visually. Fig. 7(a) shows the surface of a lead pole after 600 charge/discharge cycles, Fig. 7(b) shows the surface of a lead-acid battery after the recycling process with the application of an impulse current using the proposed DPV method. When compared to Fig. 7(a), Fig. 7(b) shows that the crystallized lead-pole surface decreased after DPV. This confirms that the crystallized sulfation on the surface of an electrode becomes spongy because of the impulse discharge [6], [7].

In this study, the effect of recycling lead-acid batteries by applying the DPV method is confirmed. However, in DPV, because there may be instances with " 0 current" during the 

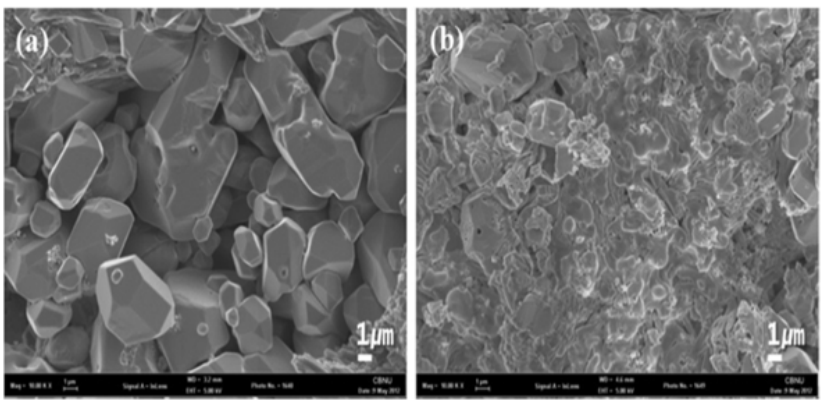

Fig. 7. SEM images of electrode. (a) Pb electrode of waste battery. (b) Renewal electrode [7].

"rest time," which means that there is no power supplied to the load, there may be a limited number of applications for batteries connected to loads that require a constant supply of power.

\section{USING LEAD-ACID BATTERIES AS ESSS}

\section{A. Controlling the Current Discharge of Lead-Acid} Batteries Using a Saw-Tooth Pulse

To use a large-capacity lead-acid battery as an ESS, the following study was performed.

First, to prevent rapid discharges, as shown in Table I, which leads to a drastic reduction in the discharge efficiency, a new method was applied to a large-capacity lead-acid battery, and the result obtained are presented in Fig. 5.

Secondly, to prevent the shortening of the life span due to sulfation on the lead-acid surface as the number of discharge cycles increases (as shown in Fig. 7(a)), an impulse-type voltage was applied to realize a reduction of sulfation in terms of the impedance change.

However, as shown in Fig. 6, the conventional DPV, which has a " 0 current" time with an "on-off"-type pulse current, adversely affects the load, which requires a constant power supply. Considering this kind of load, a new method was proposed without the " 0 current" time using a saw-tooth pulse.

An attempt was made to observe whether there was any possibility of achieving the same "rest time" effect in order to extend battery life in the saw-tooth pulse method, while the total current required for the load remains constant [29].

Fig. 8 shows an equivalent circuit of a telecommunication power supply system that requires a constant power supply, and which was implemented by applying the proposed method. Because batteries cannot autonomously control discharged currents, the role of the rectifier was changed to enable it to perform the role of the ultracapacitor of the EV in Fig. 3 for both over-charging and over-discharging. The embedded system was changed for the management of the rectifier. From Fig. 8, the proposed saw-tooth pulse applied to the battery current discharge method can be explained as follows. The current flowing through each resistor in an

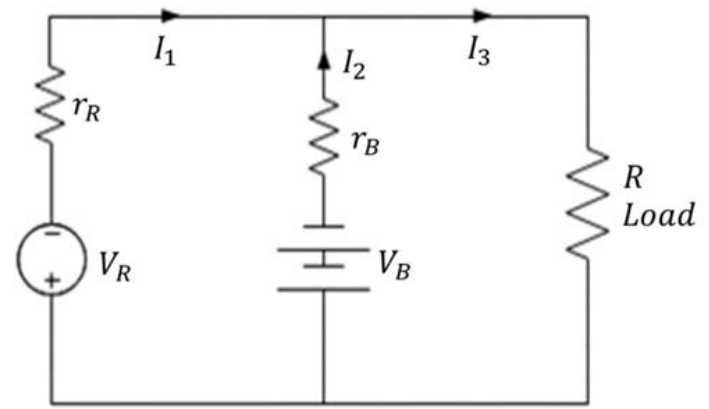

Fig. 8. Battery equivalent circuit directly connected to rectifier and load.

electrical circuit can be obtained as a solution of simultaneous equations that represent the first and second laws.

$V_{B}=$ Voltage across the Battery

$V_{R}=$ Voltage across the Rectifier

$I_{1}=$ Current through the Rectifier

$I_{2}=$ Current through the Battery

$I_{3}=$ Current through the Load

$r_{R}=$ Internal Impedence of the Rectifier

$r_{B}=$ Internal Impedence of the Battery

The equations for the current flowing through and the voltage across the individual impedances are as follows.

$$
\begin{aligned}
& V_{R}+\left(I_{1} \times r_{R}\right)+\left(I_{1}+I_{2}\right) \times R=0 \\
& V_{B}+\left(I_{2} \times r_{B}\right)+\left(I_{1}+I_{2}\right) \times R=0
\end{aligned}
$$

The following current formula is obtained from Equation (2).

$$
I_{1}=\frac{\left(V_{R}-V_{B}\right)-r_{B}}{r_{R}}
$$

$r_{R}$ and $r_{B}$ can be changed dependently by changing the ambient temperature of the rectifier, which is located in the same constant ambient temperature space. Then, Equation (4) is obtained as follows.

$$
I_{1}=k\left(V_{R}-V_{B}\right)
$$

Because the current $I_{1}$ is determined by $V_{R}$ and $V_{B}, I_{1}$ can be adjusted by the rectifier voltage $V_{R}$. Note that $V_{B}$ depends on the battery type, ambient temperature, SOC (State Of Current), and discharge duration. In addition, $r_{B}$ varies with the discharge characteristics, ambient temperature, and load conditions, and $V_{B}$ is also variable. Subsequently, by changing $V_{R}$ according to the variable $V_{B}$ and the load current $I_{3}$, it is necessary for $I_{2}$ to give a saw-tooth pulse current or a desired current wave pattern.

A simulation was conducted as explained below under the following conditions.

- The batteries are VGS $3000 \mathrm{AH}, 2.0 \mathrm{~V}, 24$ cell batteries, 2 sets, for $6000 \mathrm{AH}$.

- The rectifier is an HFRU Rectifier with an input of $380 \mathrm{~V}$ and an output of $53.5 \mathrm{~V}$.

- The actual load current averages $1200 \mathrm{~A}$.

- The discharged current is limited to $0.1 \mathrm{CA} \pm 15 \%$ of the saw-tooth pulse type. 


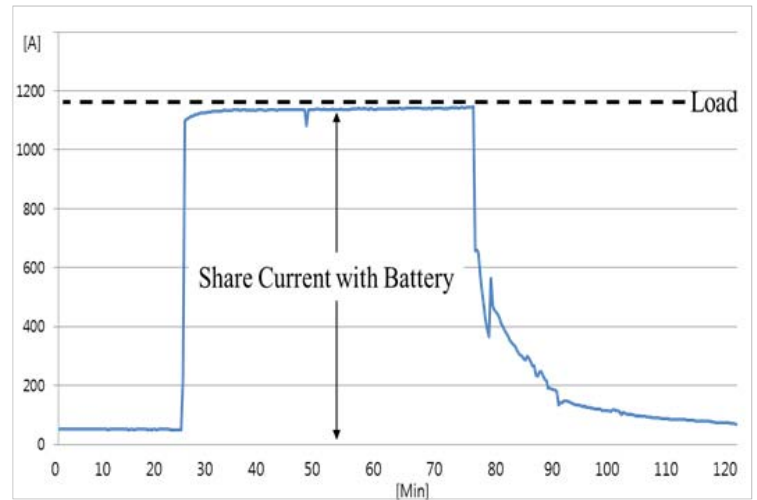

Fig. 9. Current wave in conventional method.

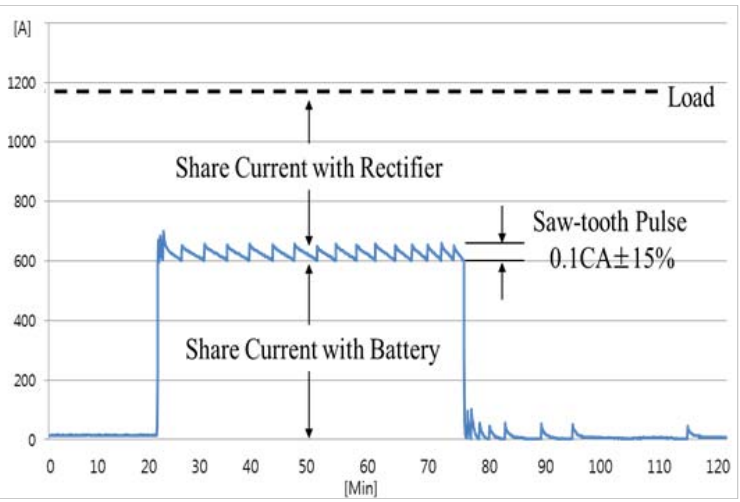

Fig. 10. Current wave in proposed method.

Fig. 9 shows the wave pattern obtained using the existing method for a current that is self-discharged from the battery, and which corresponds to the equivalent circuit state of Fig. 8 with the rectifier switched off. In this case, a load current of $1180 \mathrm{~A}$ is completely discharged from the battery, and is discharged in approximately $0.2 \mathrm{CA}$.

Fig. 10 shows the wave pattern of the current observed from the battery using the proposed SPDV (Saw-tooth Pulse Differential Voltammetry). The discharging current is limited to $0.1 \mathrm{CA} \pm 15 \%$ for the saw-tooth pulse type. Because the slope is affected by the discharging characteristics based on the battery capacity, as shown in Table I, this also affects the amplitude. With respect to the load current, a deficient current of $580 \mathrm{~A}$ is shared by the rectifier connected in parallel. This means that the load obtains the current from both the rectifier and the battery simultaneously. By comparing the existing methods with the proposed one, it can be observed that there are differences in terms of efficiency, utilization, and battery recycling effects.

First, the total discharge time is increased by a factor of 3.33 times (from $3 \mathrm{~h}$ to $10 \mathrm{~h}$ ) and the total dischargeable current is increased by $150 \%$ (from 2000 A to 3000 A) based on Table I.

Secondly, as seen in Fig. 6, because of the "0 current," the DPV method cannot be used for "on-line services" that require consistent service. However, when a pulse current is

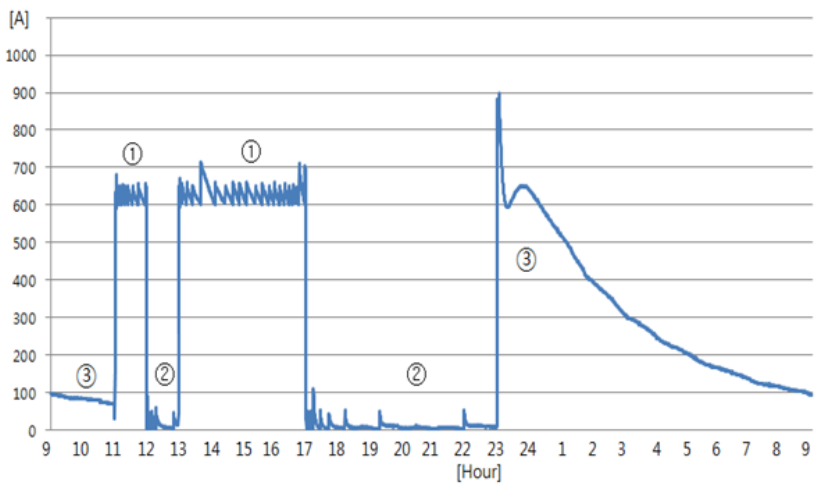

Fig. 11. Current due to saw-tooth pulse method per $24 \mathrm{~h}$.

supplied as in the SPDV of Fig. 10, a current that is up to 0.1 CA of the total battery capacity is supplied to the load without any period of " 0 current" time, while the rectifier provides the remaining supply.

Thirdly, saw-tooth pulses generated within $15 \%$ of the discharged current of 0.1 CA cause a "rest time" during which the battery can be recycled even while being operated. The recycling effect of the lead-acid battery that is realized using the proposed method will be explained in Section 5 .

\section{B. Application as an ESS under Smart Grid RTP}

Fig. 11 shows the application of lead-acid batteries as ESSs to cope with the peak energy-consumption periods and to realize energy cost savings in a smart-grid real-time pricing (RTP) environment. To minimize the energy cost required to power facilities in a building or an industry, it is necessary to (1) set the discharge period to correspond to one which attracts the highest rate, (2) ensure that the period attracting the medium pricing corresponds to a waiting period during which there is no discharging or charging, and (3) set the charging period to correspond to one which attracts the cheapest cost. The current wave pattern of Fig. 11 shows the results obtained during the application of the saw-tooth pulse method in real scenarios during the summer season. The current wave pattern of Fig. 11 shows the results obtained after the application of the saw-tooth pulse method in real scenarios during the summer season [30]-[32].

The same conditions were applied as those used for the simulation with the following conditions.

- For the discharge, the DOD (Depth Of Discharge) is $40 \%$, and the daily use is limited to a maximum of $120 \mathrm{KW}$.

- As shown in Fig. 11, daily tests were conducted in the summer during the higher priced $5 \mathrm{~h}$ period, which extends from 11-12 AM and 1-5 PM.

As shown in Fig. 11, the ESS discharges twice within (1) the most expensive period; limited charging takes place during the discharge period (2) which has medium cost; and charging takes place during (3) the cheapest period.

However, despite the voltage control, there was a current of $900 \mathrm{~A}$ for $18 \mathrm{~s}$ at 23:00 PM at the starting point of section 
(3). This was due to the indirect control through the rectifier, which is limited since the fine control cannot be the same as that for the ultra-capacitor module, as shown in Fig. 4.

\section{IMPEDANCE CHANGE AND OPERATIONAL ACHIEVEMENT EXPERIMENT}

An actual test was carried out under the same conditions as those of the simulation. The data acquisition period before the discharge test was from $10 / 10 / 12$ to $12 / 30 / 12$ (3 months) and from $01 / 02 / 13$ to $03 / 30 / 13$ (3 months, 61 working days) after the application of SPDV. For the same period from 10/01/12 to $03 / 31 / 13$ (6 months), data was acquired and sorted into groups that maintained similar charging states; i.e., groups involving the application of the proposed method and the use of batteries having the same type and manufacture date.

First, the battery discharge efficiency for the proposed method is given as follows. In Fig. $11, I_{D}$ is the discharge current (1), $I_{C}$ is the charge current, and the efficiency $\eta$ can be described as $\eta=I_{C} / I_{D}$. The results are shown in Table II.

The average efficiency for the working days from Tuesday to Friday ranges from $91.9 \%-93.4 \%$. On Saturday, no discharge took place, and the current discharged on Friday was recharged up to $12 \%$. On Monday, because the batteries were already fully charged, the ratio of the charged current to the discharged current is $107.7 \%$. The average efficiency was $92.8 \%$ when calculated in terms of the input/output efficiency.

Subsequently, as shown in Table I, the efficiency realized by the design capacity ranges from $9.8 \%$ to $39.7 \%$ after discharging for at most $15 \mathrm{~min}$ and $60 \mathrm{~min}$, respectively. However, an efficiency of $92.8 \%$ was confirmed when the proposed method was applied under the same conditions.

Secondly, an analysis of the impact of the proposed method on battery life is presented below. The technical standards committee of the IEEE made recommendations outlined in Std. 1188-1996 [33]. The technical standards were applied for the lead-acid battery conductance measurements. By doing this, non-destructive and indirect methods to determine the time-to-replacement for lead-acid batteries are recommended by performing indirect measurements of their internal impedances. According to the standards, when a battery's internal impedance increases by more than $20 \%$, followed by a sharp decrease in capacity, battery replacement is strongly recommended [34]-[40].

Under these conditions, changes in the battery life are assessed by measuring the battery impedance for the group both with and without SPDV. During the test period, checks are made to see whether there is any chance of recovering the final impedance to the initial levels.

Owing to seasonal factors, especially during the period from December to January [5], the impedance tends to
TABLE II

COMPARISON OF BATTERY EFFICIENCY DUE TO SPDV

\begin{tabular}{c|c|c|c|c|c|c|c}
\hline & Mon & Tue & Wed & Thu & Fri & Sat & Total \\
\hline Discharge: $I_{D}$ & 3160 & 3111 & 3125 & 3123 & 3126 & 0 & 15647 \\
\hline Charge: $I_{C}$ & 3008 & 3331 & 3379 & 3397 & 3386 & 353 & 16856 \\
\hline Efficiency: $\eta$ & null & $93.4 \%$ & $92.5 \%$ & $91.9 \%$ & $92.3 \%$ & null & $\mathbf{9 2 . 8 \%}$ \\
\hline
\end{tabular}

increase as the ambient temperature drops, and it decreases when the ambient temperature increases. In the test, the battery groups used for the SPDV application are called facilities $\mathrm{A}, \mathrm{B}, \mathrm{C}$, and $\mathrm{D}$, and the impedance of the first cell in each group was measured, as shown in Figs. 12(a) to 12(d).

The following device specifications were derived to measure the impedance:

- Device name: BDS (Battery Diagnosis System)

- Measurement method: pulsating wave discharge method

- Input frequency: 200 300 Hz

- Measurement range: $0.1 \mathrm{~m} \Omega \sim 99.9 \mathrm{~m} \Omega$

- Resolution: $0.001 \mathrm{~m} \Omega$

- Measurement period: once per 720 min [twice daily]

- Accuracy: $1 \%$

Fig. 12(a), shows the changes that occur from $0.31 \mathrm{~m} \Omega$ to $0.31 \mathrm{~m} \Omega$ in facility-A.

The variations that occur from $0.32 \mathrm{~m} \Omega$ to $0.33 \mathrm{~m} \Omega$ in facility-B, from $0.335 \mathrm{~m} \Omega$ to $0.335 \mathrm{~m} \Omega$ in facility-C, and from $0.36 \mathrm{~m} \Omega$ to $0.36 \mathrm{~m} \Omega$ in facility-D are shown in Figs. 12(b), 12(c), and 12(d), respectively.

As illustrated in Figs. 12(a) to 12(d), the impedance increased from $10 / 21 / 12$, when the test started for all of the batteries, and it decreased from 01/02/13, when SPDV was applied.

In the test, batteries were employed with the same manufacturer, capacity, and manufacture date that have been installed nationwide without applying the saw-tooth pulse method, as shown in Figs. 13(a) to 13(d). For convenience, the employed batteries that were called CC-A, CC-B, and CC-C, respectively.

In addition, because battery impedance is sensitive to temperature and environmental conditions, the batteries of UPS groups 1 and 2 were installed in the same location. They are VGSs with a capacity of $1000 \mathrm{AH}$ each, which were manufactured on 03/01/05, and which are named as CC-D. Figs. 13(a) to 13(d) show the measured impedances from the cells of the individual group of batteries.

Fig. 13(a) shows the waveform segment for CC-A. The impedance change between the starting point and the ending point ranges from $0.156 \mathrm{~m} \Omega$ to $0.1575 \mathrm{~m} \Omega$. Fig. 13(b) shows the CC-B battery impedance change for $0.1415 \mathrm{~m} \Omega$ to 0.143 $\mathrm{m} \Omega$. Fig. 13(c) shows the CC-C battery impedance change for $0.140 \mathrm{~m} \Omega$ to $0.141 \mathrm{~m} \Omega$. Fig. 13(d) shows CC-D for an impedance change of $0.322 \mathrm{~m} \Omega$ to $0.328 \mathrm{~m} \Omega$. 


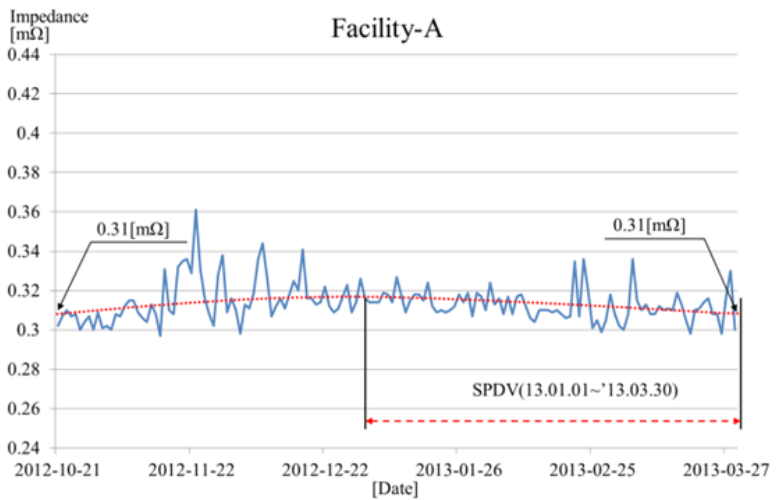

(a)

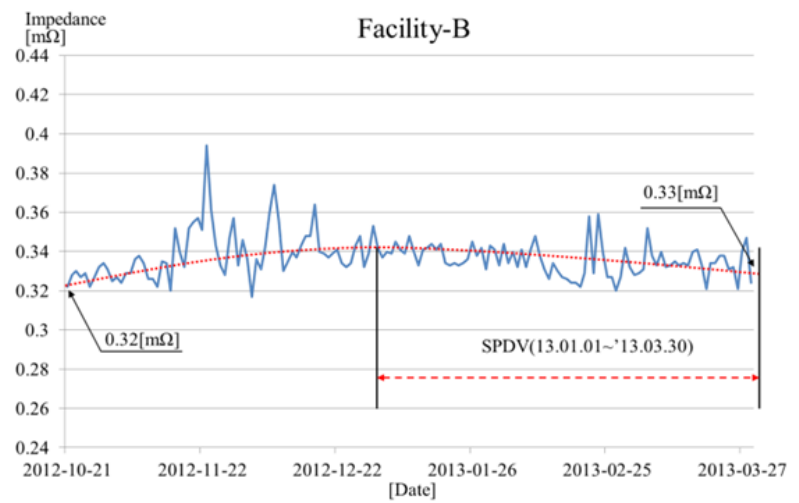

(b)

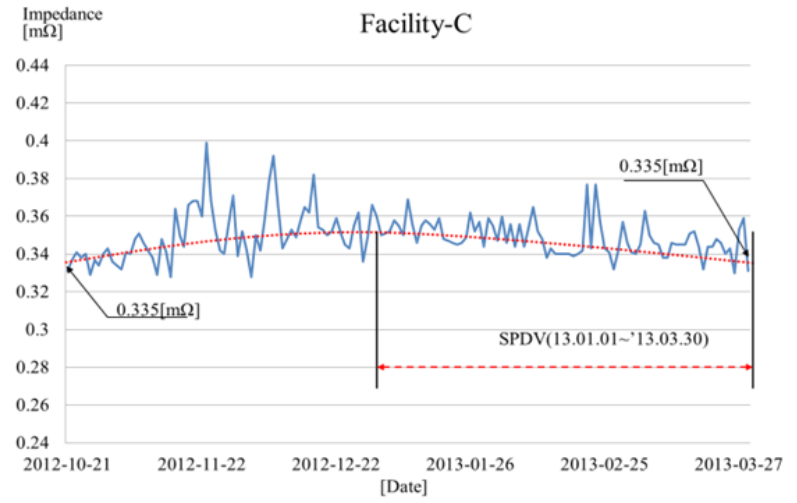

(c)

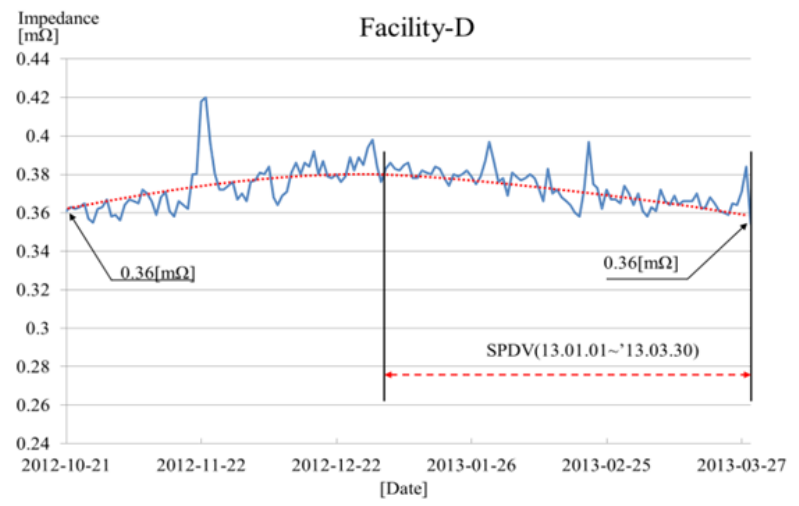

(d)

Fig. 12. Impedance variation due to SPDV. (a) Impedance variation in facility-A. (b) Impedance variation in facility-B. (c) Impedance variation in facility-C. (d) Impedance variation in facility-D.

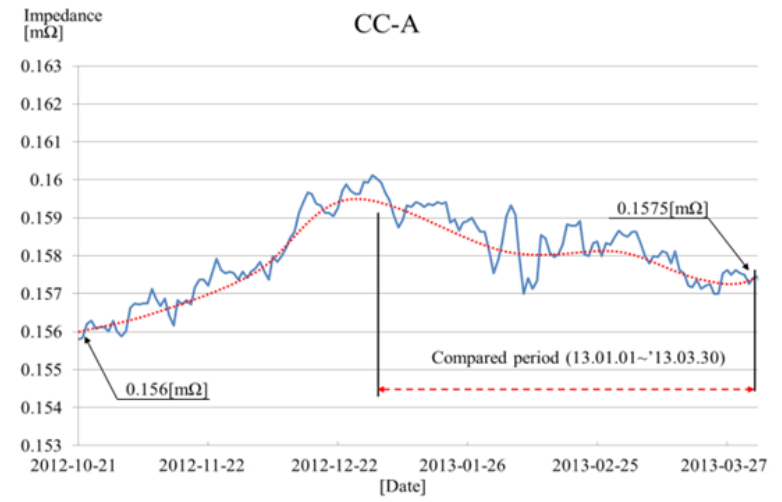

(a)

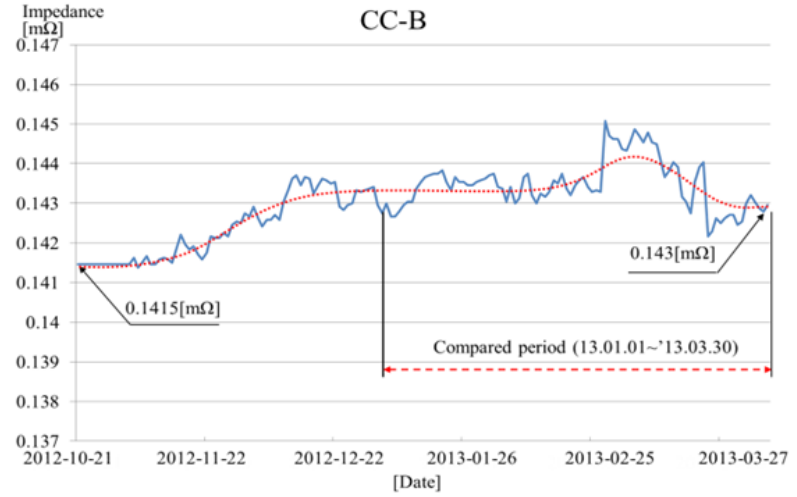

(b)

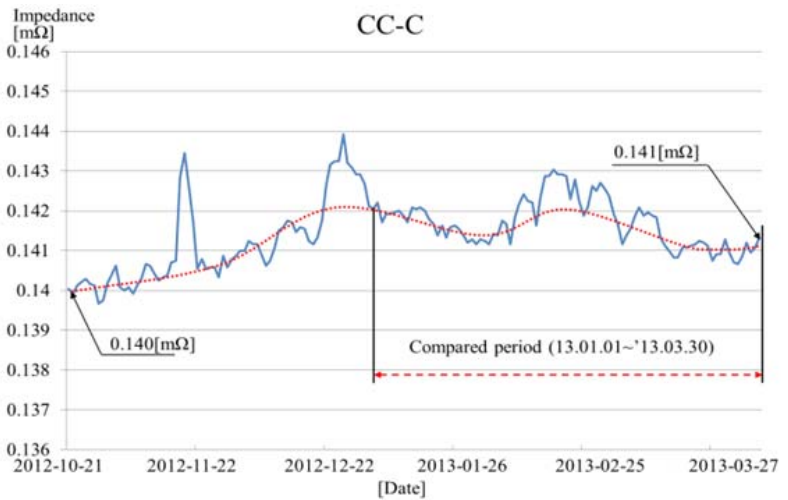

(c)

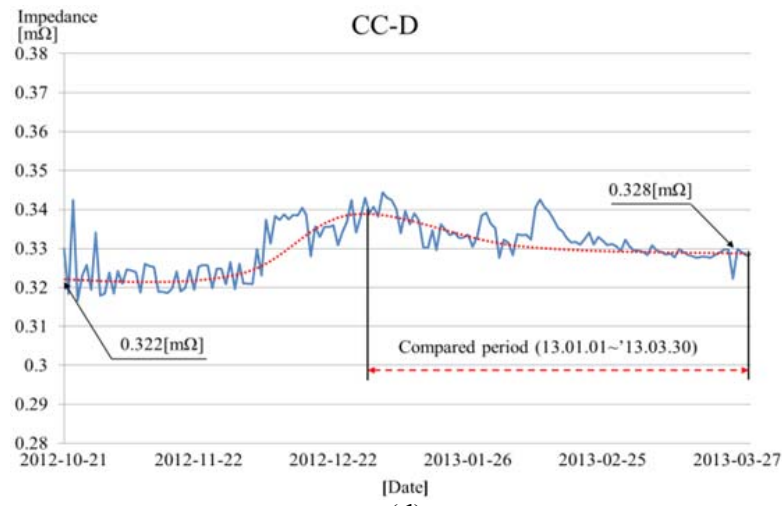

(d)

Fig. 13. Impedance variation without SPDV were adopted. (a) Impedance variation in CC-A. (b) Impedance variation in CC-B. (c) Impedance variation in CC-C. (d) Impedance variation in CC-D at the same location with the proposed method applied. 
TABLE III

Rate of Impedance Change due to the Proposed SPDV METHOD

\begin{tabular}{c|c|c|c|c|c|c|c}
\hline & Oct & Nov & Dec & Jan & Fab & Mar & Rate \\
\hline Facility-A & 0.3366 & 0.3445 & 0.3410 & 0.3373 & 0.3351 & 0.3487 & $\mathbf{9 9 . 9 0 \%}$ \\
\hline Facility-B & 0.3482 & 0.3573 & 0.3542 & 0.3495 & 0.3479 & 0.3616 & $\mathbf{9 9 . 9 3 \%}$ \\
\hline Facility-C & 0.3453 & 0.3551 & 0.3519 & 0.3474 & 0.3444 & 0.3570 & $\mathbf{9 9 . 6 7 \%}$ \\
\hline Facility-D & 0.3462 & 0.3543 & 0.3644 & 0.34686 & 0.3572 & 0.3486 & $\mathbf{9 8 . 8 5 \%}$ \\
\hline Average & 0.3441 & 0.3528 & 0.3529 & 0.3453 & 0.3462 & 0.3540 & $\mathbf{9 9 . 5 8 \%}$
\end{tabular}

TABLE IV

ImPEDANCE Change RATE Without the ApPLication of ANy METHODS

\begin{tabular}{c|c|c|c|c|c|c|c}
\hline & Oct & Nov & Dec & Jan & Fab & Mar & Rate \\
\hline CC-A & 0.1561 & 0.1571 & 0.1591 & 0.1589 & 0.1582 & 0.1575 & $\mathbf{1 0 0 . 4 9 \%}$ \\
\hline CC-B & 0.1415 & 0.1419 & 0.1432 & 0.1434 & 0.1438 & 0.1433 & $\mathbf{1 0 0 . 9 1 \%}$ \\
\hline CC-C & 0.1401 & 0.1408 & 0.1419 & 0.1416 & 0.1423 & 0.1412 & $\mathbf{1 0 0 . 5 4 \%}$ \\
\hline CC-D-1 & 0.3229 & 0.3303 & 0.3357 & 0.3341 & 0.3289 & 0.3286 & $\mathbf{1 0 0 . 2 7 \%}$ \\
\hline CC-D-2 & 0.3380 & 0.3442 & 0.3507 & 0.3490 & 0.3458 & 0.3461 & $\mathbf{1 0 0 . 7 7 \%}$ \\
\hline CC-E-1 & 0.1617 & 0.1621 & 0.1635 & 0.1641 & 0.1638 & 0.1623 & $\mathbf{1 0 0 . 6 0 \%}$ \\
\hline CC-E-2 & 0.1615 & 0.1617 & 0.1630 & 0.1635 & 0.1636 & 0.1621 & $\mathbf{1 0 0 . 6 2 \%}$ \\
\hline CC-F & 0.2022 & 0.2028 & 0.2050 & 0.2072 & 0.2085 & 0.2083 & $\mathbf{1 0 2 . 3 0 \%}$ \\
\hline Average & 0.2030 & 0.2051 & 0.2077 & 0.2077 & 0.2068 & 0.2062 & $\mathbf{1 0 0 . 7 9 \%}$ \\
\hline
\end{tabular}

Figs. 13(a) to 13(d) show that the impedance of all of the batteries started to increase from 10/21/12, when the measurements began, and reached a maximum between December and January.

As the temperature increased, it was observed that the variation in the impedance decreased. However, unlike the group involving the application of SPDV, it did not return to the initial state.

The results presented in Tables III and IV were compared. Table III shows increments of the average impedance of the total batteries that were realized with SDPV. As shown in Figs. 12(a) to 12(d), the relative impedance decreased to $99.58 \%$ before and after SDPV implementation.

Table IV shows a comparison of the rate of change of the impedance for all of the batteries as they maintain their original purpose of serving as emergency backups that are mainly used for telecommunication systems.

The same manufacturer also put forward additional battery groups of $\mathrm{CC}$, E, and F, which were not mentioned earlier, and the capacity and date of manufacture were assessed. The total average impedance increased to $100.79 \%$.

Upon application of the SPDV method, the impedance of the 8-year old batteries under experiment whose impedance degraded by more than $10 \%$ could be decreased by $0.42 \%$ over an average of only 3 months. If this is calculated for a 6 -month period, an average of $0.79 \%$ of the impedance increase is suppressed. On the other hand, a total renewal effect of $0.84 \%$ can be achieved.
Considering the 14-year lifespan recommended by the battery manufacturer $(20 \%$ impedance increase $)$, an increase of $0.79 \%$ in a 6 -month period corresponds to the normal aging process. In other words, it is possible to confirm the hypothesis that the application of normal lead-acid batteries as ESSs using the SPDV method can enhance the discharge efficiency to a level that is equivalent to that of lithium. In addition, it is possible to recover the initial impedance proportional to the service period. Nevertheless, the aging of batteries may also be affected by various physical or electro-chemical conditions. Thus, there is a need for additional long-term studies under various conditions.

\section{CONCLUSION}

By applying the SPDV method in this study, the following conclusions can be made.

First, the discharge efficiency can be enhanced by up to $92.8 \%$ under the same conditions when compared to the design efficiency of $9.8 \%$ to $39.7 \%$.

Secondly, the proposed SPDV method without the period of " 0 current" time is applicable to a constant power supply facility.

Thirdly, for experiments on batteries that are more than 8 years old, the SPDV method is shown to lower the impedance of lead-acid batteries because of the "rest time" effect through pulse current. This means that the proposed SPDV method enables lead-acid batteries to be recycled and to be simultaneously utilized as ESSs.

It has been confirmed that the proposed method makes it possible to use lead-acid batteries as ESSs with a longer life, higher efficiency, and superior utilization, even for constant power supply systems.

\section{REFERENCES}

[1] KEPCO, "Statistics from 2009 to 2010," Korea Electric Power Corporation, Jun. 2010.

[2] Y. S. Kim, "Study for power peak-cut save function improvement of PV system using LabView," Master's Thesis, KunKuk Univ., 2009.

[3] C. Min and G. A. Rincon-Mora, "An accurate electrical battery model capable of predicting runtime and $\mathrm{I}-\mathrm{V}$ performance," IEEE Trans. Energy Convers., Vol. 21, No. 2, pp. 504-511, Jun. 2006.

[4] D. Doerffel and S. A. Sharkh, "A critical review of using the Peukert equation for determining the remaining capacity of lead-acid and lithium-ion batteries," Journal of Power Sources, Vol. 155, No. 2, pp. 395-400, Apr. 2006.

[5] Se-Bang Battery CO's Laboratory, "VGS Series Battery specifications," Sep. 2011.

[6] P. Ruetschi, "Aging mechanisms and service life of lead-acid batteries," Journal of Power Sources, Vol. 127, No. 1-2, pp. 33-44, Mar. 2004.

[7] H. A. Catherino, Fred F. Feres, and F. Trinidad, "Sulfation in lead-acid batteries," Journal of Power Sources, Vol. 129, No. 1, pp. 113-120, 2003 
[8] J. Pan, C. Zhang, Y. Sun, Z. Wang, and Y. Yang, "A new process of lead recovery from waste lead-acid batteries by electrolysis of alkaline lead oxide solution," Journal of Korean Electrochemical. Commun., Vol. 19, pp. 70-72, Jun. 2012.

[9] U. Tae. J.-J. Yang, K.-M. Hong, H. J.-J Kim, and S.-G. Park, "Electrochemical renewal method for enhancing cyclic ability of lead-acid battery," Journal of Korean Electrochem. Soc., Vol. 15, No. 3, 2012.

[10] Y. J. Jang and S. J. Lee, "Battery lifetime enhancement technology using recovery effect," Journal of Inst. of Electric Sand Information Eng., Vol. 48, No. 6, pp. 33-38, Jun. 2011.

[11] R. Min and A. Chandrakasan, "Energy-efficient communication for ad-hoc wireless sensor networks," Proc. Conf. Record 35th Asilomar Conf. Signals, Systems, and Comp., Vol. 1, pp. 139-143, Nov. 2001.

[12] R. Min and A. P. Chandrakasan, "Top five myths about the energy consumption of wireless communication," ACM SIGMOBILE Mobile Commun. and Commun., rev., Vol. 6, No. 4, 2002.

[13] S. M. Lukic, S. G. Wirasingha, F. Rodriguez, C. Jian, and A. Emadi, "Power management of an Ultra-capacitor/battery hybrid energy storage system in an HEV," IEEE Vehicle Power and Propuls. Conf., VPPC '06, pp. 1-6, 2006.

[14] Z. Yu, J. Zhenhua, and Y. Xunwei, "Control strategies for battery/super-capacitor hybrid energy storage systems," The IEEE Energy 2030 Conf., pp. 1-6, 2008.

[15] B. H. Lee, "Development of energy management system for $42 \mathrm{~V}$ mild-hybrid vehicle," The Trans. of Korean Inst. of Electr. and Eng., pp. 968-969, Jul. 2006.

[16] J. H. Lee and W. Choi, "Novel state-of-charge estimation method for lithium polymer batteries using electrochemical. impedance spectroscopy," Journal of Power Electronics, Vol. 11, No. 2, pp. 237-243, Mar. 2011.

[17] J.Y. Kim, S. K. Kim, and J.H. Park, "Contribution of an energy storage system for stabilizing a microgrid during islanded operation," Journal of Electrical Engineering \& Technology, Vol. 4, No. 2, pp.194-200, Jun. 2009.

[18] C. L. Nguyen and H. H. Lee, "Optimization of wind power dispatch to minimize energy storage system capacity," Journal of Electrical Engineering \& Technology, Vol. 9, No. 3, pp.1080-1088, May 2014.

[19] S. W. Min, S. J. Kim, and D. Hur, "Optimized Installation and Operations of Battery Energy Storage System and Electric Double Layer Capacitor Modules for Renewable Energy Based Intermittent Generation," Journal of Electrical Engineering \& Technology, Vol. 8, No. 2, pp.238-243, Mar. 2013.

[20] B. H. Lee, D. H. Shin, H. S. Song, H. Heo, and H. J. Kim "Development of an Advanced Hybrid Energy Storage System for Hybrid Electric Vehicles" Journal of Power Electronics, Vol. 9, No. 1, pp. 51-60, Jan. 2009.

[21] H. S. Song, J. B. Jeong, B. H. Lee, D. H. Shin, J. Kim, and H. Heo, "Dynamic SOC compensation of an ultracapacitor module for a hybrid energy storage system" Journal of Power Electronics, Vol. 10, No. 6, pp.769-776, Nov. 2010.

[22] B. H. Lee, "A study on efficiency and cycle life improvement of hybrid energy storage systems for mild hybrid electric vehicles," PhD. Thesis, Han-Yang Univ., Aug. 2009.
[23] R. M. LaFollette, "Design and performance of high specific power, pulsed discharge, bipolar lead acid batteries," to $10^{\text {th }}$ Annual Battery Conf. on Appl. and Adv., pp. 43-47, 1995.

[24] R. M. LaFollette and D. Bennion, "Design fundamentals of high power density, pulsed discharge, lead-acid batteries. II Modeling," Journal of Electrochem. Soc., Vol. 137, pp. 3701-3707, Dec. 1990.

[25] T. F. Fuller, M. Doyle, and J. Newman, "Relaxation phenomena in lithium ion-insertion cells," Journal of Electrochem. Soc., Vol. 141, pp. 982-990, Apr. 1994.

[26] B. Nelson, R. Rinehart, and S. Varley, "Ultrafast pulse discharge and recharge capabilities of thin-metal film battery technology," 11th IEEE Int. Pulsed Power Conf., pp. 636-641, Jun. 1997.

[27] B. Nelson, "TMF ultra-high rate discharge performance," $12^{\text {th }}$ Annual Battery Conf. on Appl. and Adv., pp. 139-143, Jan. 1997.

[28] U. Tae, J.-J Yang, K.-M Hong, "Electrochemical renewal method for enhancing cyclic ability of lead-acid battery," Journal of the Korean Electrochem. Soc., Vol. 15, No. 3, pp. 160-164, 2012.

[29] H. C. Jung, "The methods and system of efficiency optimization control of battery charge and discharging in power supply equipment," KR. Patten. No. 10-2012-0143483, Dec. 11th, 2012.

[30] H. C. Jung, "Energy indicate method for the energy saves," KR. Patten. No. 10-2011-012984, Nov. $1^{\text {th }} 2011$.

[31] H. C. Jung, "A control method for the regulation energy and system for that," KR. Patten. No. 10-2011-0095135, Sep. 21th, 2011.

[32] H. C. Jung, "Devices for controlling time shift of building facility for reduction of energy cost in building and devices of controlling time shift of building facility using the same," KR. Patten. No. 10-2012-0142822, Dec. 10th, 2012.

[33] IEEE, "Testing and replacement of valve regulated lead acid (VRLA) battery for stationary application," Recommended Practice for Maintenance, IEEE Std. 1188-1996, 1996.

[34] K. S. Champlin, "Method and apparatus for measuring complex impedance of cells and batteries," United States Patent No. 6, pp. 002-238, Dec. 14, 1999.

[35] C. O. Yoon, Y. Barsukov, and J. H. Kim, "Method and apparatus for measuring battery capacity using voltage response signal based on pulse current," United States Patent No. 6, pp. 118-275, Sep. 12th, 2000.

[36] J. H. Lee, "Development of the SOC estimation method of the battery and the battery inspection system using electrochemical impedance spectroscopy," Sung-Sil Univ., Feb. 2011

[37] E. Davis and D. Funk, "New industry guidelines for the maintenance of stationary valve-regulated lead acid batteries," AVO Int. Tech. Conf., Dallas, TX, 1996.

[38] G. J. Markle, "AC impedance testing for valve regulated cell," Energy Conf., http://www.ieeexplore.ieee.org, $14^{\text {th }}$ INTELEC '92, 1992.

[39] H. S. Kim, "Diagnosis of state of health $(\mathrm{SOH})$ for battery management system (BMS)," Transactions of Korean Institute of Power Electronics(KIPE), Vol. 11, No. 6, pp. 558, Dec. 2006.

[40] M. Hlavac, D. Feder, VRLA battery conductance monitoring," Proc. of 18th Int. Telecommun. Energy Conf., pp. 632-639, 1996. 


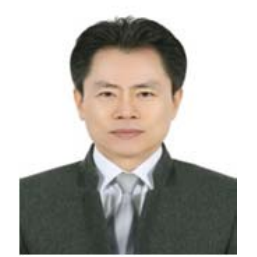

Hyun-Chul Jung received his M.S. degree in Electronics Engineering from Hanyang University in 2000 and Ph.D. degree in Control and Instrumentation Engineering from Korea University, Seoul, Korea, in 2015 respectively. Since 1996, he has been with Korea Telecom, Seoul, Korea, where he is currently a Director. His current research interests include estimator algorithms and optimum discharge algorithms for the ESSs of Smart Grids.

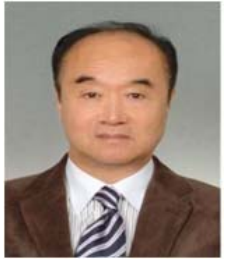

Hoon Heo received his B.S. degree in Mechanical Engineering from Korea University, Seoul, Korea, in 1975, his M.S. degree in Aerospace Engineering from the University of Texas at Austin, Austin, TX, USA, in 1981, and his Ph.D. in Mechanical Engineering from Texas Tech University, Lubbock, TX, USA, in 1985. Since 1989, he has been with the Department of Control and Instrumentation Engineering, Korea University, where he is presently a Professor Emeritus and Research Professor. His current research interests include random vibration control, stochastic system analysis and the control of vehicles. He is also involved in energy related research work. 